\title{
The solution to water shortage in Ukraine based on Multi-objective programming model
}

\author{
Bo Dong \\ School of North China Electric Power University, Baoding 071000, China
}

ABSTRACT: Proposing solution to clean water shortage is of great importance to all citizens of the world. In this paper, we do a research on water conditions of Ukraine, which indicates that a perfect intervention plan for solving the problem of water shortage is needed. We provide the solution on the two aspects, including physical and economic scarcity. On the one hand, we propose the solution for the improvement of total water resources, after the analysis of water availability in Ukraine and the factors to physical scarcity. On the other hand, we build multi-objective programming model for an intervention plan on economic scarcity, after the analysis of sewage treatment rate and demands of different aspects for water. Consequence of multi-objective programming has guiding significance for the realization of the sustainable development.

KEYWORD: water resources; physical and economic scarcity; multi-objective programming

\section{THE ANALYSIS OF WATER RESOURCES IN UKRAINE}

Total water resources are composed by three parts which present in figure 1.

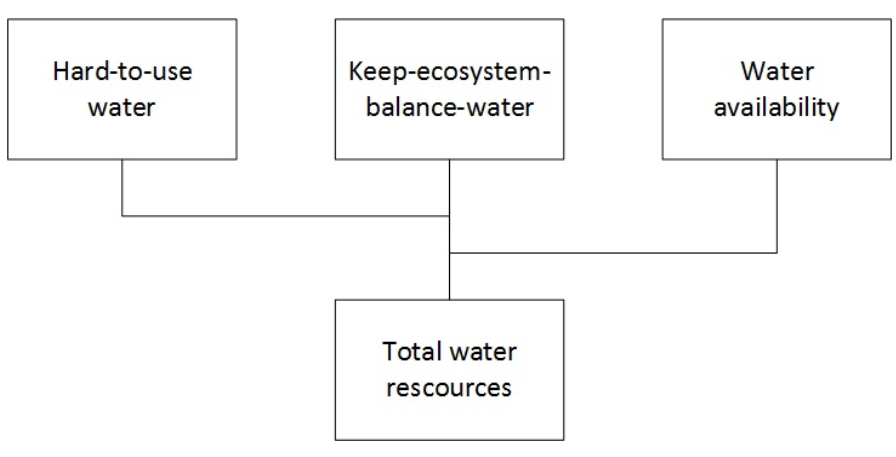

Figure 1: structure of total water availability

In the sight of utilization of water resources, studying a region of water availability is more meaningful than the total water. The accurate process of the calculation is shown below:

Water availability refers to the maximum disposable water consumption of local water resources, through employing economic-reasonable and technologically feasible measures and regarding water use from production, living and ecological system.

$P_{a}=P_{s}+P_{g}-P_{r}$

Among them, $P a$ denotes total water availability; $P s$ and $P g$ means surface and underground water respectively; $\operatorname{Pr}$ expresses the overlap water between surface and ground.
Besides, $\varepsilon$ in equation 1-2 presents the mineable coefficient, which is equal to the ratio of exploitable amount and the total, in terms of groundwater; $p 4$ and $p 5$ respectively denotes channel penetration and field infiltration.

$P_{r}=\left(p_{4}+p_{5}\right)$

In addition, $P s$ refers to surface water availability, $p 1, p 2, p 3$ separately presents total surface water, minimum ecological demand for water in river channel and the amount of flood or useless water.

$P_{s}=p_{1}-p_{2}-p_{3}$

In the light of equations above and the index value of Ukraine in 2010, we get the results of available water quantity of major rivers in Ukraine in table 8, and map presents the major rivers in Ukraine as follows:

Table 1: available water quantity of major rivers

\begin{tabular}{|l|l|l|l|}
\hline & $\begin{array}{l}\text { water } \\
\text { availa- } \\
\text { bility }\end{array}$ & $\begin{array}{l}\text { water resources } \\
\text { utilization }\end{array}$ & $\begin{array}{l}\text { total water re- } \\
\text { sources }\end{array}$ \\
\hline $\begin{array}{l}\text { dnieper } \\
\text { dniester }\end{array}$ & 141 & $41 \%$ & 341 \\
$\begin{array}{l}\text { danube } \\
\text { seversky } \\
\text { donets } \\
\text { desna }\end{array}$ & 64 & $46 \%$ & 139 \\
$\begin{array}{l}\text { southern } \\
\text { bug } \\
\text { pripyat } \\
\text { river }\end{array}$ & 14 & $46 \%$ & 145 \\
nationwide & 330 & $34 \%$ & 41 \\
\hline
\end{tabular}


We can see the ratios of water availability to the total water resources on different aspects are all dramatically under $50 \%$, which means the degree of exploitation of water resources is so poor that the water availability we use is limited.

In consideration of the problem, we draw up intervention plan on physical scarcity below:

- There is an uneven distribution of water resources in Ukraine, abundant water in the east but spare in the west.

- It is suggested that transferring the water from west to east.

- Build reservoirs in eastern of Ukraine for increasing water storage.

- Create water diversion from the surrounding countries such as Russia in map.

- The best advice is that digging a river from Cherkasy to Mykolaya in map.

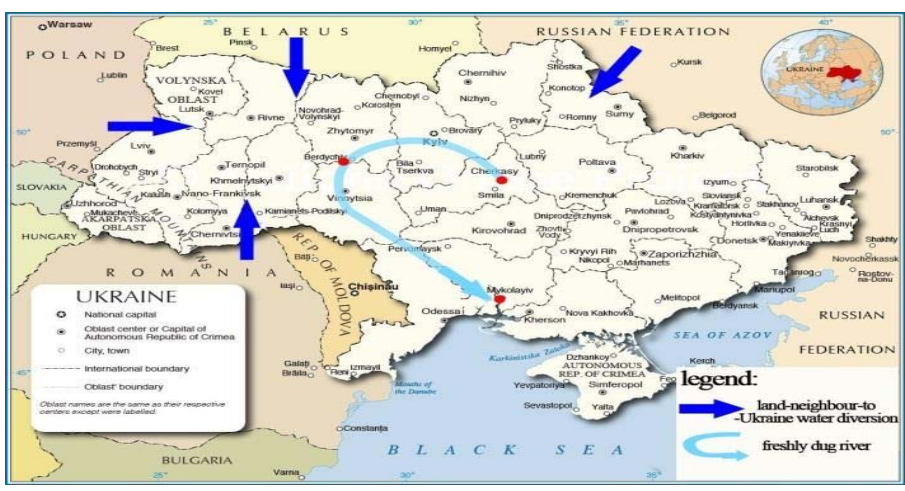

Figure2:water diversion map

\section{THE SOLUTION TO ECONOMIC SCARCITY}

Making a suitable solution in terms of economic scarcity is necessary. We apply multi-objective programming model for water allocation, which will ensure the social economic resources and coordinated development between ecological and environment.

Considering water resources influences not only social and economic benefits, but also ecological benefits. We regard these benefits as target, water availability, environmental capacity and others as constraint conditions for building multi-objective programming.

First of all, establish objective functions:

$z=\max \left\{S(u), E(u), E_{v}(u)\right\}$

$\left\{\begin{array}{c}G(u) \leq 0 \\ u \geq 0\end{array}\right.$

Where let u denotes decision vector, $\mathrm{S}(u), E(u)$, $E_{v}(u)$ expresses respectively social, economic and ecological benefits. Additionally, the constraint set, including total available water resources, capacity of ecological environment and so on, is denoted by $\mathrm{S}(u)$.
Meanwhile, the district is divided into $\mathrm{K}$ sub zones $(k=1,2, \cdots \mathrm{K})$, and we define there are $\mathrm{J}(\mathrm{k})$ water departments in sub zone $\mathrm{k}$ and $\mathrm{L}$ water resources in the objective district. Besides, let $M_{c}{ }^{k}(c=1,2, \cdots, L)$ present the quantity of water distributed to sub zone k.

Based on the above, determine objective and constraint functions. As follow:

\section{- Objective functions}

$>$ Social benefits

As it is not easy to measure this target, we suppose human demands for water reflect social benefits in a degree.

$$
\operatorname{maxS}(\mathrm{u})=-\min \left\{\sum_{k=1}^{K} \sum_{j}^{J(k)}\left[M_{J}^{k}-\sum_{c=1}^{l} x_{c j}^{k}\right]\right\}
$$

$>$ Economic benefits

$\operatorname{maxE}(\mathrm{u})=-\min \left\{\sum_{k=1}^{K} \sum_{j}^{J(k)}\left[\sum_{c=1}^{L} x_{c j}^{k} \alpha_{c j}^{k} \beta_{c j}^{k} \omega_{k}\right]\right\}$

Where $\alpha_{c j}{ }^{k}$ denotes efficiency correction coefficient of $x_{c j} k ; \beta_{c j} k$ formulates fairness correction coefficient of $x_{c j}$; $\omega_{k}$ expresses the weight coefficient of sub zone $\mathrm{k}$.

$>$ Ecological benefits

$$
\begin{aligned}
& \max E_{v}(\mathrm{u})= \\
& -\min \left\{\sum_{k=1}^{K} \sum_{j}^{J(k)}\left[0.01 d_{j}^{k} p_{j}^{k} \sum_{c=1}^{L} x_{c j}^{k}\right]\right\}
\end{aligned}
$$

\section{- Constraint equations}

$>$ Supply capacity

$\sum_{j=1}^{E(\mathrm{k})} x_{c j}^{k} \leq M_{c}^{k}$

$>$ Water-carrying capacity of the water conveyance system

$x_{c j}^{k} \leq Q_{c}$

$>$ The change of people's supply and demands for water

$M_{j L}^{k} \leq \sum_{c=1}^{L} x_{c j}^{k} \leq x_{j H}^{k}$

$>$ Tonnage of drainage system

$z k j t \leq z 0 t$

$>$ Ecological environment restriction

$\sum_{k=1}^{K} \sum_{Z=1}^{Z} x_{z}{ }^{k} \leq S^{k}$

$>$ Non-negative constraints

$x_{c j} k \geq 0$

Based on the balance among social, economic and ecologic benefits, we provide intervention plan on economic scarcity:

- Establish water station for agricultural irrigation and improve sewage treatment rate.

- Introduce edicts and regulations or policies for water conservation

- Detect freshwater resources unknown as well as reduce the desalination cost. 
- Improve the level of education in order to raise citizen's awareness of saving water.

\section{EVALUATION OF THE SOLUTION}

- Advantages

1) The water supply ability and water utilization rate are improved obviously

2) It is helpful to balance the distribution of water and strengthen the steady of ecosystem.

- Disadvantages

3) Intervention plan may cost too much both on personal, financial and material resources, which may break the original economic development in Ukraine.

4) Multi-objective optimization configuration of water may have a negative impact on ecology, industry and agriculture.

\section{CONCLUSIONS}

By analyzing water condition in Ukraine, we found it is necessary to take some action to prevent it. According to the multi-objective programming model, we acquired optimal water allocation, which is beneficial to making up a suitable intervention plan for Ukraine.

\section{REFERENCES}

[1] Zhonggeng Han, Mathematical modeling method and its application. Higher Education Press, 2005, p.91-107,343-364.

[2] Shoukui Si,Xiqing Sun, Mathematical modeling. National Defense Industry Press, 2011, p.353-355.

[3] Wang Xian-jia. Multi objective analysis method for sustainable utilization of water resources[J]. Systems Engineering- Theory \& Practice, 2001, 21(3)128-135.

[4] Zhouting Guo. A preliminary analysis of the estimation of water resources available[J]. SHUI WEN, 2001, 21(5)23-26.

[5]--Yiping Qi. Optimal Scheduling of Networked Water Resource System[D]. Beijing.2011. 